\title{
CSF Tau proteins reduce misdiagnosis of sporadic Creutzfeldt- Jakob disease suspected cases with inconclusive 14-3-3 result
}

\author{
M. J. Leitão $0^{1,5}$ • I. Baldeiras ${ }^{1,4,5} \cdot$ M. R. Almeida ${ }^{5}$ M. H. Ribeiro ${ }^{1,4}$ •

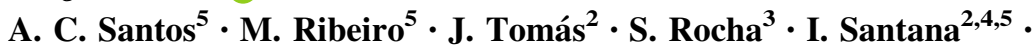 \\ C. R. Oliveira ${ }^{1,2,4,5}$
}

Received: 28 April 2016/Revised: 13 June 2016/Accepted: 14 June 2016

(C) Springer-Verlag Berlin Heidelberg 2016

\begin{abstract}
Cerebrospinal fluid (CSF) 14-3-3 protein supports sporadic Creutzfeldt-Jakob (sCJD) diagnosis, but often leads to weak-positive results and lacks standardization. In this study, we explored the added diagnostic value of Total Tau (t-Tau) and phosphorylated Tau (p-Tau) in SCJD diagnosis, particularly in the cases with inconclusive 14-3-3 result. 95 definite sCJD and 287 patients without prion disease (non-CJD) were included in this study. CSF samples were collected in routine clinical diagnosis and analysed for 14-3-3 detection by Western blot (WB). CSF t-Tau and p-Tau were quantified by commercial ELISA kits and PRNP and APOE genotyping assessed by PCR-RFLP. In a regression analysis of the whole cohort, 14-3-3 protein revealed an overall accuracy of $82 \%$ (sensitivity $=96.7 \%$; specificity $=75.6 \%$ ) for sCJD. Regarding 14-3-3 clear positive results, we observed no added value either of t-Tau alone or $\mathrm{p}$-Tau/t-Tau ratio in
\end{abstract}

\section{J. Leitão \\ jajao86@gmail.com}

1 Neurochemistry Laboratory, Neurology Department, University Hospital Coimbra, Centro Hospitalar e Universitário de Coimbra, Praceta Mota Pinto, 3000-075 Coimbra, Portugal

2 Neurology Department, University Hospital Coimbra, Centro Hospitalar e Universitário de Coimbra, Praceta Mota Pinto, 3000-075 Coimbra, Portugal

3 Neurology Department, St Marcos Hospital, Sete Fontes, São Victor, 4710-243, Braga, Portugal

4 Faculty of Medicine, University of Coimbra, Faculdade de Medicina, Pólo III, Azinhaga de Santa Comba, Celas, 3000-548 Coimbra, Portugal

5 CNC.IBILI-Center for Neuroscience and Cell Biology, University of Coimbra, Rua Larga, 1st floor, 3004-504 Coimbra, Portugal the model. On the other hand, considering 14-3-3 weakpositive cases, t-Tau protein increased the overall accuracy of 14-3-3 alone from 91 to $94 \%$ and specificity from 74 to $93 \%(p<0.05)$, with no sensitivity improvement. However, inclusion of $\mathrm{p}$-Tau/t-Tau ratio did not significantly improve the first model $(p=0.0595)$. Globally, t-Tau protein allowed a further discrimination of $65 \%$ within 14-3-3 inconclusive results. Furthermore, PRNP MV genotype showed a trend to decrease 14-3-3 sensitivity $(p=0.051)$, but such effect was not seen on $\mathrm{t}$-Tau protein. In light of these results, we suggest that t-Tau protein assay is of significant importance as a second marker in identifying 14-3-3 false-positive results among SCJD probable cases.

Keywords sCJD · CSF - 14-3-3 protein - Biomarkers · Tau protein $\cdot$ Phosphorylated Tau protein

$\begin{array}{ll}\text { Abbreviations } \\ \text { SCJD } & \text { Sporadic Creutzfeldt-Jakob } \\ \text { Non-CJD } & \text { Non-prion disease } \\ \text { CSF } & \text { Cerebrospinal fluid } \\ \text { LP } & \text { Lumbar puncture } \\ \text { CNS } & \text { Central nervous system } \\ \text { t-Tau } & \text { Total Tau protein } \\ \text { p-Tau } & \text { Phosphorylated Tau protein } \\ \text { ELISA } & \text { Enzyme-linked immunosorbent assay } \\ \text { WB } & \text { Western blot } \\ \text { AD } & \text { Alzheimer's disease } \\ \text { APOE } & \text { Apolipoprotein E gene } \\ P R N P & \text { Prionic protein gene } \\ \text { PrPSc } & \text { Scrapie prion protein } \\ \text { EEG } & \text { Electroencephalogram } \\ \text { MRI } & \text { Magnetic resonance imaging } \\ \text { WHO } & \text { World health organization }\end{array}$


RPD Rapidly progressive dementia

RT-QuIC Real-time quaking-induced conversion

\section{Introduction}

Sporadic Creutzfeldt-Jakob disease (sCJD) is the most common human transmissible spongiform encephalopathy, causing a rapidly progressive neurodegeneration and ultimately leading to the patient's death within months to few years [1]. Like other human spongiform encephalopathies, it is characterized by the accumulation of pathological prion protein (PrPSc) in the central nervous tissue. Recent technical developments, allowing the reliable ultrasensitive detection of PrPSc in body fluids [2, 3], will hopefully provide a much more disease specific test during patient lifetime. However, to the moment, definitive diagnosis of sCJD remains highly dependent on neuropathological examination and immunochemical demonstration of PrPSc in brain tissue [4].

The probable diagnosis of sCJD is based, not only on the clinical features and course of the disease [5], (a rapidly progressive dementia with less than 2-year duration together with at least two of the following symptoms: myoclonus, ataxia, pyramidal or extrapyramidal signs, akinetic mutism, visual, and psychiatric disturbances), but also on electroencephalography (EEG), magnetic resonance imaging (MRI), and cerebrospinal fluid (CSF) findings [6]. The heterogeneity of symptoms, especially in early course of the disease, may resemble other irreversible rapidly progressive dementias (RPDs), however, a small proportion of patients may have a potentially treatable condition [7], and, therefore, an accurate and rapid diagnosis of these patients is of paramount importance.

Since its introduction in the WHO diagnostic criteria for sCJD, CSF analysis has become increasingly important in the differential diagnosis of RPDs. Immunodetection of protein 14-3-3 in CSF was originally demonstrated to have a high sensitivity and specificity for SCJD [8, 9]. International collaborative studies [10], as well as single center studies [11-14], have shown that in the appropriate clinical circumstances, a positive 14-3-3 protein detection correlates with clinical diagnosis in 85-94\% of cases. However, this view has been challenged by findings of poor specificity $[15,16]$, and low sensitivity in autopsy-proven sCJD cases [17]. In addition, it has been shown that the sensitivity of 14-3-3 test is also influenced by disease duration $[10,12,13]$ and by the prion molecular sub-type, with a decrease in sensitivity for PrP-type 2 and PRNP codon 129 heterozygotes [10, 13, 14, 18].

Another major limitation of the 14-3-3 analysis is the lack of standardization of the assay between laboratories. The analysis of 14-3-3 protein is usually done using
Western blotting (WB), which is usually analysed in a qualitative manner, prone to interrater variability. Interpretation of borderline results (weak-positive) is also a subjective issue, with less than half of the patients with weak-positive CSF 14-3-3 results corresponding to sCJD cases, suggesting that the diagnostic utility of weak-positive 14-3-3 results is limited [19]. Moreover, during the last years, a marked increase in 14-3-3 test referrals for sCJD diagnosis in various reference laboratories has been observed [20, 21].

To overcome the limitations of the 14-3-3, other brainderived proteins have been studied in the CSF of sCJD patients, and total Tau protein ( $\mathrm{t}$-Tau) has shown promising results. CSF t-Tau reaches extremely high levels in sCJD, probably reflecting the extent of the neurodegenerative process, and its clinical utility has been previously reported by us [14] and others [11, 12, 22, 23], with sensitivity ranging from 87 to $94 \%$ and specificities of 90-100\%. Interestingly, recently published studies have suggested $\mathrm{t}$-Tau as the single best marker for sCJD [24, 25], particularly in early stage sCJD [26], with increased specificity compared to 14-3-3 [19, 27]. As specificity is highly dependent on the population investigated (group of patients with a defined neurological condition vs. control group of individuals without dementia vs. cohort of mixed pathologies with a clinical suspicion of sCJD), it is very difficult to compare individual studies on t-Tau specificity. In fact, several cut-off levels for CSF t-Tau in SCJD have been proposed, but vary between centers. Therefore, the comparative value between t-Tau and 14-3-3 detection is still an open question, and only limited information on $\mathrm{t}$-Tau in the differential diagnosis of RPD is available [28].

Unlike what happens in Alzheimer's disease (AD), hyperphosphorylation of Tau and formation of neurofibrillary tangles do not occur in sCJD, and so, phosphorylated Tau (p-Tau) alone does not seem to be a useful marker for sCJD. However, the ratio between $\mathrm{p}$-Tau and $\mathrm{t}$-Tau levels ( $\mathrm{p}$-Tau/t-Tau) has shown to improve discrimination between $\mathrm{AD}$ or other RPDs and SCJD, with lower levels in favour of the latter [14, 24, 29, 30]. Only limited information is available on $\mathrm{p}$-Tau/t-Tau ratio optimal cutoff levels and its comparative value in relation to 14-3-3 or $\mathrm{t}$-Tau alone [31]. Along with the introduction of these alternative CSF markers in laboratories worldwide, questions about the sensitivity, specificity, and added value of these assays, although recognised as extremely useful, have been raising.

In this study, conducted in the framework of the Portuguese Epidemiological Surveillance Program for Human Prion Diseases and of a Joint Programming for Neurodegenerative Diseases (JPND) European project (DEMTEST-biomarker-based diagnosis of rapid progressive dementias_optimisation of diagnostic protocols), 
we aim to evaluate the added value of Tau proteins ( $t$-Tau and the p-Tau/t-Tau ratio), next to the conventional sCJD biomarker 14-3-3, in a population of patients with a clinical suspicion of sCJD. In parallel, we also focus on the discriminatory potential between SCJD and non-CJD patients, particularly in cases with a weak-positive 14-3-3 result. The influence of $A P O E$ and $P R N P$ genetical profile on the diagnostic accuracy of the CSF markers is also explored.

\section{Materials and methods}

\section{Patient characterization}

Patients with a clinical suspicion of CJD, recruited from different hospitals across the country, were included in this study. Their CSF and blood samples were collected as part of their routine clinical diagnosis investigation and sent to our laboratory for the detection of 14-3-3 protein in CSF. Of the 872 samples received between April 2000 and December 2012, 675 were also submitted to t-Tau and p-Tau quantification. Within these, follow-up diagnosis from 382 cases was reported back to the laboratory by the responsible physician. Herein, we only report the results from the patients for whom a confirmatory diagnosis was available: 95 neuropathologically confirmed sporadic CJD (sCJD) and 287 patients proved to have an alternative diagnosis (non-CJD), as this was our inclusion criteria. Therefore, all probable and possible cases as well as the two cases of variant CJD [32] and three of Fatal Familiar Insomnia (Santana et al., personal communication) that have been identified in our population, were excluded from this study.

The diagnosis of definite SCJD was made according to the standard international agreed criteria [6], including post-mortem neuropathological confirmation or brain biopsy. In the non-CJD group, the appropriate diagnosis criteria were used. This group included patients with other neurodegenerative diseases $(n=181,63 \%)$, metabolic encephalopathies $(n=33,11.5 \%)$, CNS inflammatory/ infectious diseases $(n=16,5.6 \%)$, psychiatric conditions $(n=18,6.3 \%)$, neoplastic syndromes $(n=8,2.8 \%)$, autoimmune diseases $(n=8,2.8 \%)$, vascular diseases ( $n=6,2.1 \%)$, epilepsy $(n=4,1.4 \%)$, and other diseases $(n=13,4.5 \%)$. These clinical probable diagnoses were established by a senior neurologist, considering clinical data review, ancillary investigation, and evolution.

\section{CSF proteins evaluation: 14-3-3, t-Tau, and p-Tau}

CSF samples, collected in sterile polypropylene tubes, were centrifuged at $2500 \mathrm{rpm}$ for $5 \mathrm{~min}$, aliquoted and stored at $-80{ }^{\circ} \mathrm{C}$ until analysis. Immunodetection of protein 14-3-3 in CSF was done as described previously [14]. Briefly, CSF proteins were separated by sodium dodecyl sulphate-polyacrylamide gel electrophoresis, and detection was carried out by incubation with mouse anti-14-3-3 beta monoclonal antibody (sc-1657, Santa Cruz Biotechnology, USA) followed by horseradish peroxidase-conjugated antimouse immunoglobulin (DakoCytomation, Denmark). Membranes were developed by enhanced chemiluminescence (SuperSignal, West Pico, PIERCE, USA) and imaged on film (Eastman Kodak Company, Rochester, NY, USA). A positive and a weak-positive control (CSF from patients with histopathologically confirmed sporadic CJD with a strong- or a weak-protein 14-3-3 signal, respectively) and a negative control (CSF from a patient without histological evidence of CJD and showing no protein 14-33 signal) were included in the run. All samples were tested twice and the result evaluated by three independent observers. In cases of contradictory results or when an agreement between the observers could not be reached, a third test was made to establish a final result. As an external quality control measure, we participated in ring trials for WB 14-3-3 detection, where intervariability across centers was addressed.

CSF t-Tau and p-Tau-181 were measured by commercially available sandwich ELISA kits (Innotest, Innogenetics, Ghent, Belgium), according to the manufacturer instructions, as previously reported [14]. Whenever the readings for $\mathrm{t}$-Tau were above the highest standard used in the calibration curve $(1200 \mathrm{pg} / \mathrm{mL})$, CSF sample was appropriately diluted to give readings within the linear part of the calibration curve. All samples were analysed in duplicate, and the p-Tau to t-Tau ratio was calculated. External quality control of the assays was performed under the scope of the Alzheimer's Association Quality Control Program for CSF Biomarkers [33], using trial samples three times a year, including a long-term storage CSF control which has been the same since 2011 and tested several times with reproducible values.

All assays were performed sequentially in a clinical routine setting.

\section{$A P O E$ and $P R N P$ genotyping}

A sub-set of 243 patients was genotyped for APOE (59 sCJD and 184 non-CJD) and 196 patients for PRNP (62 sCJD and 134 non-CJD). Blood samples were collected into EDTA tubes and DNA was isolated from whole blood using a commercial kit (Roche Diagnostics GmbH, Manheim, Germany), as described by the manufacturer.

The analysis of the two polymorphisms at codons 112 and 158 of the $A P O E$ gene (rs429358 and rs7412) was determined by polymerase chain reaction-restriction 
fragment length polymorphisms (PCR-RFLP) assay, as previously described [34].

The analysis of the PRNP M129Vpolymorphism (rs 1799990) was performed by PCR using specific primers (F5'-GAC AGC CTC ATG GTG GTG GC and R5'-CACA TCT GCT CAA CCA CGC GC) followed by restriction $N s p I$ digestion. The resulting fragments were separated by electrophoresis and gel interpretation was performed independently by two observers.

\section{Statistical analysis}

Statistical analysis was performed using the program Statistical Package for the Social Sciences (SPSS, version 21.0) (IBM SPSS, Chicago, IL) and graphs built using GraphPad Prism 6.0. Normality of continuous variables was assessed by the Kolmogorov-Smirnov test. Differences in demographical, clinical, and biochemical continuous variables between diagnostic groups were examined using either Student's $t$ test (for variables with normal distribution) or the Mann-Whitney $U$ (for variables that did not show normal distribution). Kruskal-Wallis followed by Mann-Whitney $U$ was used for comparing protein levels between PRNP genotypes. $\chi^{2}$ test was used to assess differences between categorical variables. Logistic regression analysis was used to identify the best sub-set of biomarkers for pairwise discrimination. The chosen method was "enter", diagnostic group (sCJD or non-CJD) was set as the dependent variable, and age, gender, and disease duration were set as independent variables. Tau protein and p-Tau to $\mathrm{t}$-Tau ratio were added one at a time to the first model (just 14-3-3). The first combination of variables resulted in Model 2 and the other in Model 3. Sensitivity, specificity, positive and negative likelihood ratios ( $\mathrm{LR}+/ \mathrm{LR}-$ ), and overall accuracy were derived from the models. Receiveroperating characteristics (ROC) curve analysis was used to evaluate not only the diagnostic accuracy of the different isolated markers, but also the predicted probabilities derived from the models. Those ROC curves were further compared according to the AUC comparison method of Hanley and McNeil, 1983, using MedCalc (version 13.1) (MedCalc Software, Mariakerke). Optimal cut-off values for each parameter that yielded the highest Youden index [sensitivity + (specificity -1$)]$ were selected. A decision tree was made using the Chi-squared automatic interaction detection method (CHAID). The maximum tree depth was set to three levels, the significance for splitting nodes and merging categories was set to 0.05 , the maximum number of iterations was 100 , the minimum number of cases in parent nodes was 10 and for a child node 5, and the minimum change in expected cell frequencies was 0.001. CJD population was targeted as our classification variable (with positive state). We have inserted 14-3-3, t-Tau and p-Tau as classifying variables, and the model decided which biomarker was best to reach a final diagnosis and displayed the number of cases corresponding to CJD diagnosis or other (non-CJD).

\section{Results}

\section{Clinical and molecular characterization of the patients}

The principal features of all patients for whom a final diagnosis was available are summarized in Table 1 . There were small, but significant differences regarding gender distribution and age between the SCJD and the non-CJD group, with $83 \%$ of sCJD patients being older than 60 years at the time of lumbar puncture vs. $65 \%$ of the non-CJD group $(p=0.03)$. Disease duration at the time of lumbar puncture was also significantly shorter in the SCJD group, with $86 \%$ of sCJD patients having a disease duration inferior to 12 months (70\% in the non-CJD group; $p=0.001$ ). Most patients had a negative family history of dementia (98\% of sCJD and $92 \%$ of non-CJD patients; $p>0.05$ ). We also assessed the prevalence of symptoms in sCJD and non-CJD patients at the time of lumbar puncture (not shown). Dementia was present in all patients, and at least one other symptom was present in all SCJD patients and over $90 \%$ of non-CJD patients. Myoclonus, ataxia, and akinetic mutism were significantly more common in the SCJD group (74, 74 and $41 \%$, respectively, vs. 35,26 and $18 \%$ in non-CJD patients, $p<0.0001$ for all comparisons). Extrapyramidal or pyramidal signs and psychiatric problems were equally found in both groups (55\% in SCJD vs. $49 \%$ in non-CJD and $59 \%$ in SCJD vs. $67 \%$ in non-CJD). Visual problems were the least common of symptoms, showing also no difference between SCJD and non-CJD patients (31\% in SCJD vs. $21 \%$ in non-CJD).

Concerning molecular characteristics, PRNP codon 129 genotyping was available in 196 patients (62 sCJD and 134 non-CJD) (see Table 1). MM genotype was the most prevalent, accounting for half the total number of patients. Although MM genotype frequency was higher in SCJD patients (61 vs. $46 \%$ in non-CJD), there were no significant differences between groups, even when considering homozygous patients altogether (MM + VV) vs. heterozygous (MV). Within the SCJD group, there was a trend for individuals with MM genotype to be older at time of diagnosis and the heterozygous to present longer disease duration ( $p=0.051$; not shown). Information regarding the $A P O E$ polymorphism was available in 243 patients (59 SCJD and 184 non-CJD). The distribution of the different APOE genotypes was neither statistically different between the diagnostic groups, nor there were differences regarding 
Table 1 Clinical features and principal investigation findings of all patients

\begin{tabular}{|c|c|c|}
\hline & $\operatorname{SCJD}(n=95)$ & Non-CJD $(n=287)$ \\
\hline Gender (M/F) & $45 / 50$ & $163 / 124$ \\
\hline Age, years ${ }^{\mathrm{a}}(\min -\max )$ & $67.6 \pm 9.7 *(34-87)$ & $\begin{array}{l}63.8 \pm 13.6 \\
(19-91)\end{array}$ \\
\hline Duration disease, months ${ }^{\mathrm{a}}(\min -\max )$ & $4.7 \pm 4.8^{* * *}(1-21)$ & $\begin{array}{l}12.2 \pm 18.5 \\
(1-120)\end{array}$ \\
\hline ApoE genotype (59 CJD; 184 non-CJD) & $\begin{array}{l}\varepsilon 2 \varepsilon 3-5(8.5 \%) \\
\varepsilon 2 \varepsilon 4-0 \\
\varepsilon 3 \varepsilon 3-43(73 \%) \\
\varepsilon 3 \varepsilon 4-11(18.5 \%) \\
\varepsilon 4 \varepsilon 4-0\end{array}$ & $\begin{array}{l}\varepsilon 2 \varepsilon 3-18(10 \%) \\
\varepsilon 2 \varepsilon 4-1(0.5 \%) \\
\varepsilon 3 \varepsilon 3-117(63.5 \%) \\
\varepsilon 3 \varepsilon 4-42(23 \%) \\
\varepsilon 4 \varepsilon 4-6(3 \%)\end{array}$ \\
\hline PRNP codon 129 genotype (62 CJD; 134 non-CJD) & $\begin{array}{l}\mathrm{MM}-38(61 \%) \\
\mathrm{MV}-16(26 \%) \\
\mathrm{VV}-8(13 \%)\end{array}$ & $\begin{array}{l}\text { MM-61 (46\%) } \\
\text { MV-51 (38\%) } \\
\text { VV-22 (16\%) }\end{array}$ \\
\hline EEG-typical/total (\%) & $38 / 67(57)^{* * *}$ & $14 / 170(8)$ \\
\hline MRI—characteristic/total (\%) & $21 / 43(49) * * *$ & $9 / 134(7)$ \\
\hline 14-3-3 protein (pos/Wp/neg) & $68 / 25 / 2 * * *$ & $3 / 83 / 201$ \\
\hline $\mathrm{t}-\mathrm{Tau}(\mathrm{pg} / \mathrm{mL})^{\mathrm{b}}$ & $7417 \pm 9801 * * *$ & $276.5 \pm 1502$ \\
\hline $\mathrm{p}-\mathrm{Tau}(\mathrm{pg} / \mathrm{mL})^{\mathrm{b}}$ & $35.5 \pm 24.0^{* *}$ & $25.5 \pm 25.5$ \\
\hline p-Tau/t-Tau $(\times 100)^{\mathrm{b}}$ & $0.53 \pm 2.3 * * *$ & $12 \pm 8.4$ \\
\hline
\end{tabular}

Pos positive, $W p$ weak-positive, neg negative

$* p<0.05$ vs. non-CJD; $* * p<0.01$ vs. non-CJD; $* * * p<0.0001$ vs. non-CJD

${ }^{a}$ Data are expressed as mean $\pm \mathrm{SD}$

${ }^{b}$ Data are expressed as median \pm SD the frequency of the $\varepsilon 4$ allele. The most prevalent form was $\varepsilon 3 \varepsilon 3$ ( $65.8 \%$ of all patients) followed by $\varepsilon 3 \varepsilon 4(21.8 \%)$. Only $18.5 \%$ of sCJD patients carried one $\varepsilon 4$ allele, and there were no $\varepsilon 4$ homozygous patients, whereas in the nonCJD group, $26.5 \%$ had at least one $\varepsilon 4$ allele, with six homozygous patients.

Results regarding diagnostic tests, other than the 14-3-3 assay, performed in SCJD suspected cases, are also shown in Table 1. An EEG result was available for 58 sCJD and 158 non-CJD patients. The number of positive EEGs in the sCJD group was statistically higher than the number of typical sCJD-EEG results in the non-CJD group, resulting in a sensitivity of $55 \%$ and a specificity of $92 \%$. Cerebral MRI had been performed in only 35 sCJD and 135 nonCJD patients, showing a rather low sensitivity (40\%), but a very high specificity $(93 \%)$.

\section{CSF biomarkers: 14-3-3, t-Tau, and p-Tau}

CSF 14-3-3 immunoblot showed a very high sensitivity (98\%), with 93 out of 95 sCJD patients presenting with a signal in the WB. Within 14-3-3 positive SCJD samples, 68 gave a clear positive result ( $72 \%$ ), while 25 were weakpositive signals ( $26 \%$ ). Only 2 sCJD patients had a negative 14-3-3 result: one was a young woman (age 47), with an isolated dementia evolving over a two-year period, with no investigational features, except for the MRI, suggestive of sCJD and PRNP genotype MV, whose final diagnosis was made following brain biopsy [18]; the other was a 73-yearold male, presenting with dementia, extrapyramidal signs, psychiatric problems and a typical sCJD-EEG, 1-year disease duration at time of LP, and also with a PRNP MV genotype. In the non-CJD groups, only 3 patients $(1 \%)$ showed a clear positive 14-3-3 band, but 83 (29\%) presented with weak-positive signals, resulting in a rather low specificity of 70\%. 14-3-3 positive and weak-positive nonCJD cases, divided by the different diagnostic sub-groups are shown in Table 2. Overall, around $25-40 \%$ of patients with other neurodegenerative, inflammatory/infectious, metabolic, epileptic, or vascular diseases gave a weak/positive signal, while in psychiatric and autoimmune conditions, weak/positive signals were seen in approximately $15 \%$ of patients. In patients with the neoplastic conditions, more than half had a weak-positive 14-3-3 result. The three non-CJD patients that gave a clear 14-3-3 positive signal were all cases of encephalopathies: one patient in postanoxic state in context of prolonged ill partial complex; one autoimmune, associated with presence of antibodies antipotassium voltage channels, and the one case of Wernicke encephalopathy. Amongst the group of neurodegenerative disorders, $\mathrm{AD}$ was the most prevalent $(n=58 ; 32 \%)$, followed by frontotemporal lobar degeneration (FTLD, 
Table 2 Findings for tested protein markers according to the different sub-groups within non-CJD patients

\begin{tabular}{|c|c|c|c|c|c|}
\hline Clinical group, $N$ (\% non-CJD) & Age (years) & Dis. duration, (months) & $14-3-3$ pos/Wp, $N(\%)$ & $\mathrm{t}-\mathrm{Tau} \operatorname{pos}, N(\%)$ & $\mathrm{p}-\mathrm{Tau} / \mathrm{t}-\mathrm{Tau}$ pos, $N(\%)$ \\
\hline $\begin{array}{l}\text { Neurodegenerative } \\
181(63.0 \%)\end{array}$ & $66.6 \pm 11.7$ & $15.4 \pm 20.2$ & $0 / 51(28.2 \%)$ & $12(6.6 \%)$ & $12(6.6 \%)$ \\
\hline $\begin{array}{l}\text { Metabolic } \\
33(11.5 \%)\end{array}$ & $58.1 \pm 12.4$ & $9.6 \pm 22.7$ & $1 / 13(43.8 \%)$ & $3(9.4 \%)$ & $5(15.6 \%)$ \\
\hline $\begin{array}{l}\text { Inflammatory/infectious } \\
16(5.6 \%)\end{array}$ & $60.3 \pm 15.9$ & $7.2 \pm 3.9$ & $0 / 5(31.2 \%)$ & $0(0 \%)$ & $2(12.5 \%)$ \\
\hline $\begin{array}{l}\text { Psychiatric } \\
18(6.3 \%)\end{array}$ & $53.6 \pm 17.3$ & $7.2 \pm 8.6$ & $0 / 3(16.7 \%)$ & $0(0 \%)$ & $1(5.6 \%)$ \\
\hline $\begin{array}{l}\text { Neoplastic } \\
8(2.8 \%)\end{array}$ & $65.4 \pm 11.7$ & $1.9 \pm 0.8$ & $0 / 5(62.5 \%)$ & $0(0 \%)$ & $1(12.5 \%)$ \\
\hline $\begin{array}{l}\text { Autoimmune } \\
8(2.8 \%)\end{array}$ & $52.1 \pm 23.5$ & $5.3 \pm 3.8$ & $1 / 0(12.5 \%)$ & $1(12.5 \%)$ & $1(12.5 \%)$ \\
\hline $\begin{array}{l}\text { Vascular } \\
6(2.1 \%)\end{array}$ & $69.8 \pm 9.3$ & $3.0 \pm 0.7$ & $0 / 3(50 \%)$ & $0(0 \%)$ & $1(25 \%)$ \\
\hline $\begin{array}{l}\text { Epilepsy } \\
4(1.4 \%)\end{array}$ & $72.5 \pm 4.6$ & $4.0 \pm 2.2$ & $1 / 0(25 \%)$ & $1(25 \%)$ & $1(25 \%)$ \\
\hline $\begin{array}{l}\text { Other diseases } \\
13(4.5 \%)\end{array}$ & $61.5 \pm 14.6$ & $2.7 \pm 1.9$ & $0 / 3(23.1 \%)$ & $2(15.4 \%)$ & $2(15.4 \%)$ \\
\hline
\end{tabular}

Age and disease duration were assessed at the time of lumbar puncture and are expressed as mean \pm SD

14-3-3 pos/Wp: number of positive and weak-positive cases out of totals

t-Tau pos: $>1039 \mathrm{pg} / \mathrm{mL}$

p-Tau/t-Tau pos: $<4.36$

$n=33 ; 18 \%)$; vascular dementia $(n=23 ; 13 \%)$; Lewy body dementia ( $n=20 ; 11 \%)$; Parkinson's disease $(n=9$; $5 \%$ ), mixed dementia ( $n=7 ; 4 \%$ ); corticobasal degeneration $(n=7 ; 4 \%)$; multiple system atrophy $(n=6 ; 3 \%)$; progressive supranuclear palsy $(n=4 ; 2 \%)$, and other neurodegenerative dementias $(n=14 ; 8 \%)$. In all these neurodegenerative disorders sub-groups, 20-40\% of patients had a weak-positive 14-3-3 result (not shown), except for the 4 patients with progressive supranuclear palsy, that were all negative for 14-3-3.

CSF concentrations of t-Tau and p-Tau, as well as the $\mathrm{p}$-Tau/t-Tau ratio for both sCJD and non-CJD patients are shown in Table 1 and in Fig. 1. CSF t-Tau was, as we had previously reported [14], markedly increased in SCJD patients ( $p<0.0001)$, whereas CSF p-Tau levels were only slightly increased $(p=0.012)$. These differences in CSF $\mathrm{t}$-Tau and $\mathrm{p}$-Tau resulted in a marked decrease in the $\mathrm{p}$-Tau/t-Tau ratio in the sCJD group $(p<0.0001)$. Single marker ROC curve analysis depicted that t-Tau alone (cutoff $=1039 \mathrm{pg} / \mathrm{mL}$ ) could distinguish sCJD from non-CJD patients with a sensitivity of $95 \%$ and a specificity of $94 \%$, with an AUC of 0.983 (95\% CI 0.972-0.994; $p<0.001)$. p-Tau did not reach enough discrimination power, as the AUC from its ROC curve was below 0.8 and for that reason was next discarded for the regression analysis. For the $\mathrm{p}$-Tau/t-Tau ratio $($ cutoff $=0.0436$ ), sensitivity was $96 \%$ and specificity $91 \%$, with and AUC of 0.972 (95\% CI $0.950-0.994 ; p<0.001$ ), not statistically different from the ROC curve obtained with t-Tau $(p=0.203)$. Although sensitivity was slightly lower as compared with the 14-3-3 immunoblot, an increase in specificity was found for Tau proteins. This increase in specificity was seen across almost all the different diagnostic sub-groups within non-CJD patients (Table 2), with less than $10 \%$ of patients with other neurodegenerative and metabolic diseases testing positive for t-Tau, and none in the inflammatory/infectious, psychiatric, neoplastic, and vascular conditions groups. No increase in specificity was seen in the small group of patients with autoimmune or epileptic encephalopathies, with the two patients that were clear positive for 14-3-3 also testing positive for t-Tau and $\mathrm{p}$-Tau/t-Tau ratio.

\section{Added value of combining CSF markers}

To assess the value of adding CSF Tau proteins to 14-3-3 in the diagnostic workout of patients with a clinical suspicion of sCJD, we performed the multiple logistic regression analysis with diagnosis (sCJD vs. non-CJD) as the dependent variable and age, gender, duration of disease, and either CSF 14-3-3 alone or with t-Tau and p-Tau/t-Tau ratio as independent categorical variables (Table 3 ). The model 


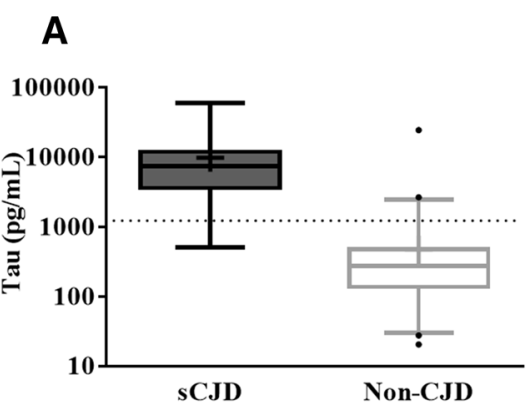

Fig. 1 Box plots of CSF: a t-Tau, b p-Tau, and c p-Tau 181/t-Tau $(\times 100)$ ratio in SCJD and non-CJD patients. Plots show 10th, 25th, 50th, 75th, and 90th percentiles and outliers. The dotted line represents the optimal cut-off levels between SCJD with non-CJD
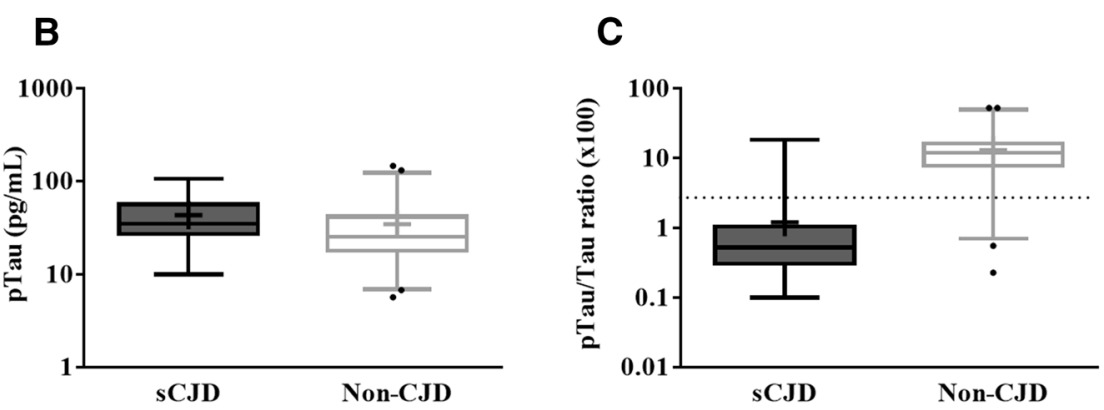

Table 3 Logistic regression models for distinction between SCJD and non-CJD patients

\begin{tabular}{lllllll}
\hline Variables included & Sens $(\%)$ & Spec $(\%)$ & AUC $(95 \%$ CI $)$ & OA $(\%)$ & LR(+) & LR(-) \\
\hline All cases $(n=354)$ & & & & & & \\
Model 1 & 96.7 & 75.6 & $0.882(0.845-0.918)$ & 81.9 & 3.96 & 0.04 \\
Model 2 & 94.5 & 94.6 & $0.966(0.946-0.985)^{* * *}$ & 94.3 & 17.5 & 0.06 \\
Model 3 & 96.7 & 93.0 & $0.961(0.935-0.987)^{* * *}$ & 94.0 & 13.8 & 0.04 \\
14-3-3 pos and neg $(n=255)$ & & & & & \\
Model 1 & 97.0 & 98.4 & $0.973(0.943-1.000)$ & 98.0 & 60.6 & 0.03 \\
Model 2 & 98.5 & 96.2 & $0.990(0.977-1.000)$ & 98.0 & 25.9 & 0.02 \\
Model 3 & 97.0 & 98.4 & $0.979(0.950-1.000)$ & 98.0 & 60.6 & 0.03 \\
14-3-3 Wp and neg $(n=286)$ & & & & & \\
Model 1 & 92.6 & 74.1 & $0.832(0.758-0.906)$ & 90.6 & 3.58 & 0.1 \\
Model 2 & 92.6 & 93.3 & $0.948(0.908-0.988)^{*}$ & 94.3 & 13.8 & 0.08 \\
Model 3 & 92.6 & 94.1 & $0.936(0.868-1.000)$ & 93.6 & 15.7 & 0.08 \\
\hline
\end{tabular}

Model 1: 14-3-3 only; Model 2: 14-3-3 + Tau; and Model 3: 14-3-3 + p-Tau/t-Tau ratio. $\mathrm{LR}(+)=$ positive likelihood ratio (sensitivity $-(1-$ specificity $)) ; \operatorname{LR}(-)=$ negative likelihood ratio $((1-$ sensitivity $) /$ specificity $)$. AUC $=$ area under the curve, determined by the ROC analysis of the predicted probability determined by the models. All regression models included age, duration of disease, and gender as covariates

$* p<0.05$ vs. model, including just the 14-3-3 assay; *** $p<0.0001$ vs. model, including just the 14-3-3 assay

that included 14-3-3 (both positive and weak-positive results considered as positive) as the only CSF marker, presented a sensitivity of $97 \%$ and specificity of $76 \%$ with an overall accuracy of $82 \%$, a LR + of 3.96 and a LR - of 0.04. Adding CSF t-Tau to the model (positive if $>1039 \mathrm{pg}$ / $\mathrm{mL}$ ), slightly decreased sensitivity to $95 \%$, but significantly increased specificity also to $94.6 \%, \mathrm{LR}+$ to 17.5 , LR - to 0.06 and overall accuracy to $94 \%(p<0.0001)$. The logistic regression model obtained by addition of $\mathrm{p}$-Tau/t-Tau ratio (positive if $<0.0436$ ) was also statistically different from the one containing only 14-3-3 maintaining sensitivity in $97 \%$ and improving overall accuracy to $94 \%$ and specificity to $93 \%(p<0.0001)$. However, it was not better than t-Tau as a second biomarker.

To further explore the added value of Tau in relation to the 14-3-3 protein assay, we repeated the above analysis, patients, as determined by the ROC curve analysis for: a Tau $>1039 \mathrm{pg} / \mathrm{mL}$ and $\mathbf{c} \mathrm{p}$-Tau/t-Tau ratio $\times 100<4.36$. $* * * p<0.0001$ vs. non-CJD. $Y$ axis displayed in $\log 10$ scale 
to $94 \%$ and overall accuracy from 91 to $94 \%$, although not significantly $(p=0.0595)$ and had no impact on sensitivity.

Subsequently, the three CSF assays (14-3-3, t-Tau, and $\mathrm{p}$-Tau/t-Tau ratio) were entered in a decision tree model to discriminate between the two diagnostic groups (sCJD vs. non-CJD). As the 14-3-3 assay is the only CSF marker currently included by the WHO in the diagnostic criteria for sCJD, we initially decided to force 14-3-3 protein as the first variable of the model. As shown in Fig. 2a, the final decision model retained only CSF 14-3-3 and t-Tau. In a first step, the population was divided into three groups according to the 14-3-3 assay, with the group with a negative 14-3-3 result retaining $70 \%$ of non-CJD patients (201/287) and just 2 sCJD patients (2\%). On the other hand, the group with a positive 14-3-3 result retained $72 \%$ of sCJD patients (68/95) and only 3 non-CJD patients (1\%). The group with a weak-positive 14-3-3 result (including 108 subjects; $28 \%$ of the study population) was then further divided into three sub-groups, according to the t-Tau levels, with the sub-group with the lowest t-Tau levels accounting for 52 of the remaining 83 non-CJD patients, and the group with the highest t-Tau levels retaining 18 of the remaining 25 sCJD patients. The subgroup with intermediate t-Tau levels (38 subjects) remained 31 non-CJD patients and 7 sCJD subjects, without a conclusive result. Overall, this decision tree model correctly classified $89 \%$ of the study population, including 253 non-CJD (88\%) and 86 sCJD patients (91\%).

When 14-3-3 protein was not forced as the first variable in the decision tree model (Fig. 2b), this resulted in a model with a higher overall diagnostic accuracy (96\%) that classified correctly 285 non-CJD (99 \%) and 83 sCJD patients $(87 \%)$. However, as a first variable, the model chose $\mathrm{t}$-Tau, dividing the population into three groups: low t-Tau $(<901 \mathrm{pg} / \mathrm{mL})$, that included $92 \%$ of the non-CJD patients $(265 / 287)$ and only 5 sCJD patients (5\%); intermediate t-Tau $(901 \leq \mathrm{t}-\mathrm{Tau} \leq 2983)$, that retained 38 subjects and was further divided according to the 14-3-3 assay as positive (10 sCJD and 1 non-CJD) or weak-positive + negative (20 non-CJD and 7 sCJD); and high t-Tau ( $>2983 \mathrm{pg} / \mathrm{mL}$ ), that retained the remaining $73 \mathrm{sCJD}$ patients $(77 \%)$ and only 1 non-CJD individuals $(0.3 \%)$.

\section{Influence of age and disease duration on protein markers}

Age at the time of diagnosis ( $<60$ vs. $\geq 60$ years $)$ did not influence the sensitivity of either of the CSF markers tested for sCJD patients (Fig. 3a), nor it had any effect on the mean values of t-Tau, $\mathrm{p}$-Tau, or the $\mathrm{p}$-Tau/t-Tau ratio (not shown; $p>0.05$ for all comparisons). When we divided sCJD patients according to disease duration at the time of lumbar
Fig. 2 Decision tree models using CSF 14-3-3 and t-Tau to discriminate between sCJD and non-CJD patients, forcing or not 14-3-3 as the first variable in the model. SCJD is targeted as state variable. Correctly classified patients are depicted in bold. a 14-3-3 is forced as first variable and Tau is added by the model only to weakpositive cases. b Without forcing any variable, the decision model sets Tau as classifying variable and further adds 14-3-3 to discriminate within those cases with intermediate Tau levels

puncture ( $<12$ vs. $\geq 12$ months), a CSF $14-3-3$ protein positive test in SCJD patients was more frequently associated with shorter disease duration ( $p<0.0001$; Fig. 3b). Likewise, t-Tau values were higher $(<12 \mathrm{M}=10,307 \pm$ $10,035 \mathrm{pg} / \mathrm{mL} ; \quad \geq 12 \mathrm{M}=6654 \pm 12,298 \mathrm{pg} / \mathrm{mL} ; \quad p=$ $0.027)$ and the p-Tau/t-Tau ratio was lower $(<12 \mathrm{M}=$ $0.011 \pm 0.023 ; \geq 12 \mathrm{M}=0.022 \pm 0.018 ; p=0.034)$ in sCJD patients with shorter disease duration of disease, although no influence in overall sensitivity of these markers was observed. Age and duration of disease did not influence the levels of any of the protein markers in the non-CJD group (data not shown).

\section{Influence of $A P O E$ and $P R N P$ genotypes on protein markers}

We looked for an influence of the $A P O E$ and PRNP genotype on the levels of the protein markers assessed (data not shown). This analysis is obviously limited by the very low frequency of some of the genotypes. We did not find any influence of the APOE genotype on the levels of $\mathrm{t}$-Tau and $\mathrm{p}$-Tau in any of the diagnostic groups. Concerning PRNP genotype, homozygoty for valine was associated with the highest t-Tau levels in sCJD patients $(21,392 \pm 18,240 \mathrm{pg} / \mathrm{mL}$ vs. $6368 \pm 7361 \mathrm{pg} / \mathrm{mL}$ in $\mathrm{MV}$, $p<0.01$ ), and heterozygous with the lowest (vs. MM $10,102 \pm 8567 \mathrm{pg} / \mathrm{mL} p<0.05)$. The same effect of the valine allele was seen for $\mathrm{p}$-Tau values, with the VV subjects having the highest levels $(72 \pm 22.5 \mathrm{pg} / \mathrm{mL}$ vs. MV $38.3 \pm 16.5$ and MM $35 \pm 18 \mathrm{pg} / \mathrm{mL}, p=0.001$ ), but not for the $\mathrm{p}$-Tau/t-Tau ratio, although MV genotype still presented significantly higher ratios than the MM group $(1.6 \pm 1.6$ vs. MV $0.53 \pm 0.45$ and $\mathrm{MM} 0.91 \pm 1.8$, $p=0.032$ ). Among the non-CJD group, PRNP genotype only influenced $\mathrm{p}$-Tau/t-Tau ratio, where VV patients had the lowest ratios facing others $(0.106 \pm 0.103$ vs. MV $0.14 \pm 0.07$ and MM $0.13 \pm 0.06, p=0.023)$.

In the sCJD group, we also examined the influence of PRNP codon 129 polymorphism on the sensitivity of the different markers. A positive 14-3-3 result was found in all homozygotes (MM and VV), while the sensitivity of this test was tendentiously lower for the MV genotype ( $p=0.05$, Fig. 3c). Neither for t-Tau or $\mathrm{p}$-Tau/t-Tau ratio was the sensitivity influenced by the PRNP codon 129 polymorphism ( $p>0.05$; Fig. $3 c)$. 


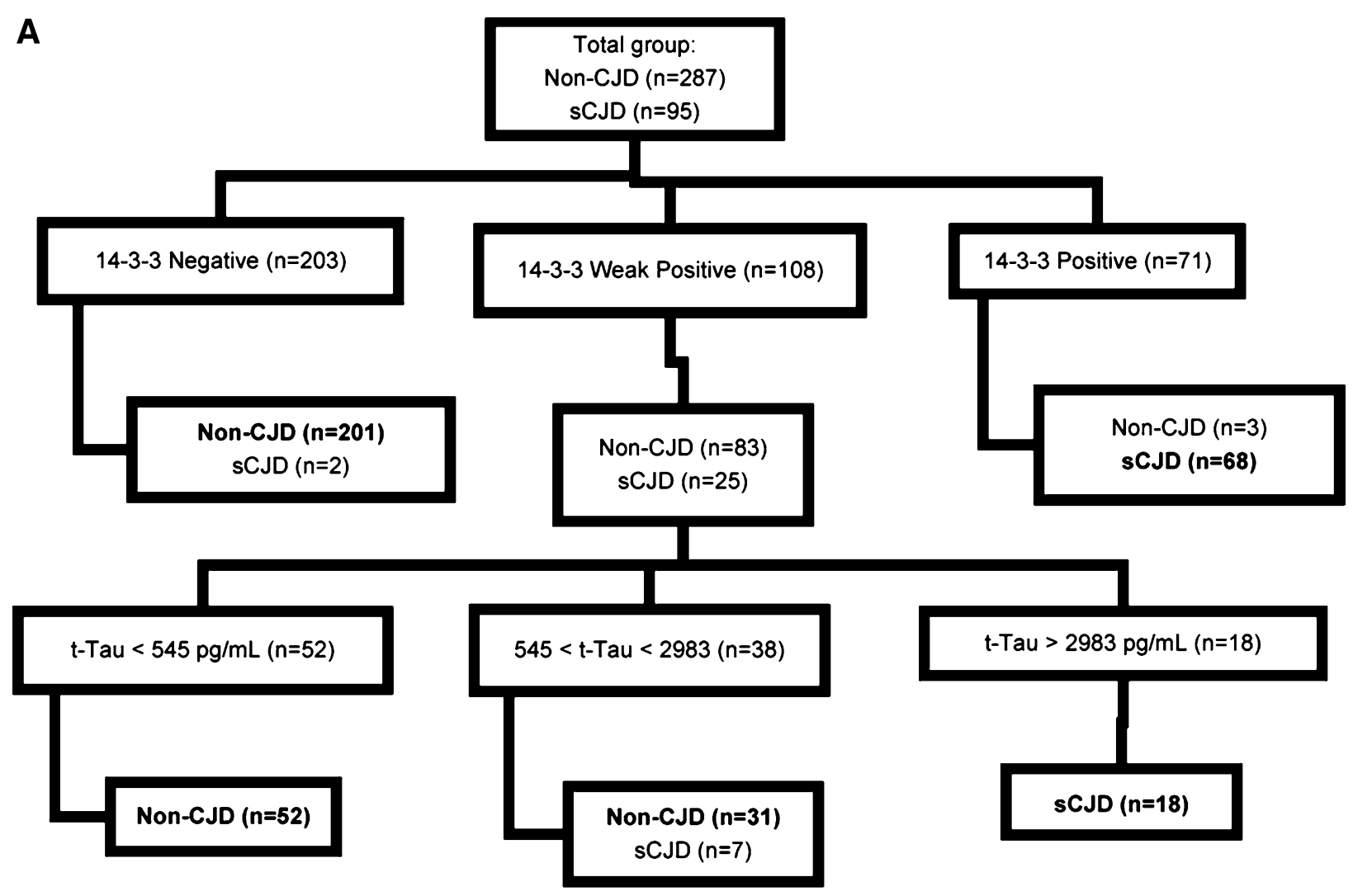

B

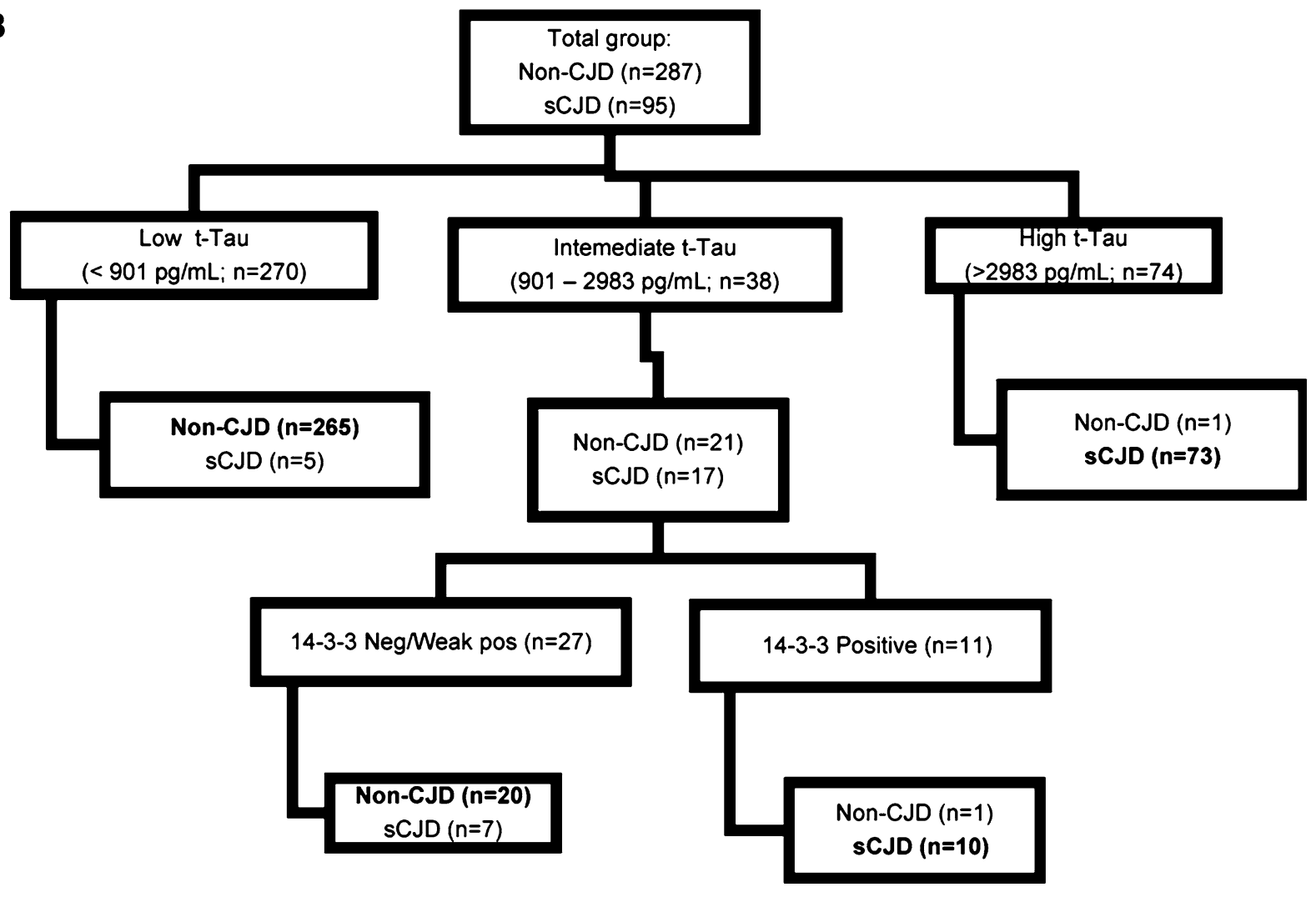



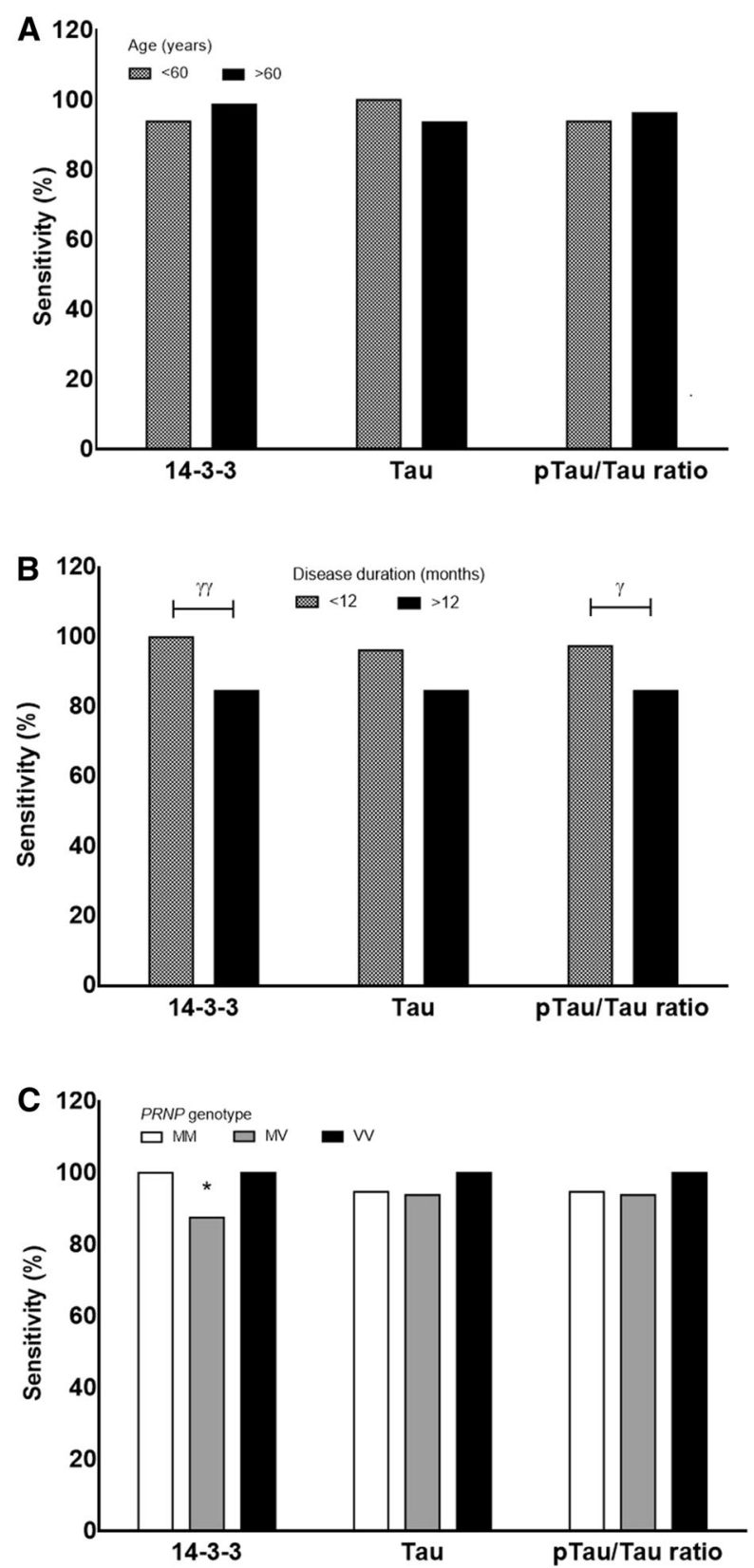

Fig. 3 Effect of age, disease duration, PRNP codon 129, and APOE genotype in the sensitivity of CSF markers for sCJD. Age and disease duration were assessed at the time of lumbar puncture. 14-3-3(+): all bands considered; t-Tau $(+):>1039 \mathrm{pg} / \mathrm{mL} ; \mathrm{p}$-Tau/t-Tau $(+):<4.36$. ${ }^{*} p=0.05$ vs. MM/VV; ${ }^{\gamma} p<0.05$ vs. $>12$ months disease duration; ${ }^{\gamma \gamma} p<0.0001$ vs. $>12$ months disease duration

\section{Discussion}

In this work, we assessed the added value of t-Tau and the p-Tau/t-Tau ratio, on the diagnostic accuracy of patients with a clinical suspicion of sCJD. Overall, our results showed that Tau protein levels and p-Tau/t-Tau ratio add diagnostic value to 14-3-3 results, particularly in weakpositive cases, where $65 \%$ of the cases could be further clarified. Besides, $P R N P$ and $A P O E$ genotype showed no impact on Tau sensitivity, contrary to 14-3-3.

Our study group consisted of 382 patients: 95 definite sCJD patients, presenting with a rapidly progressive dementia, associated in most cases with myoclonus and ataxia; and a control group of 287 patients, with a clinical suspicion of SCJD, but in whom an alternative diagnosis was reached (non-CJD). All non-CJD patients presented with dementia, and in most cases, another symptom (most often psychiatric problems), could be found. In accordance to what has been reported by others [7,20,35], roughly two -thirds of non-CJD patients suffered from non-reversible disorders, with $\mathrm{AD}$ being the single most prevalent group, and one-third had a potentially treatable disease. Our study group was selected amongst a total of 872 patients that were referred to our laboratory for CSF 14-3-3 determination between 2000 and 2012 and for whom a final diagnosis was reached. Clearly, the percentage of patients that had an available confirmatory diagnosis is low (44\% of all samples received), and this is a limitation of this study. In addition, the low autopsy rate, in relation to the total number of samples that tested positive or weakpositive for 14-3-3, restricted the number of samples included and probably introduced some bias to the study. In fact, from all patients that had a clear positive 14-3-3 result during this timeframe $(n=147)$, only $68(46 \%)$ were submitted to autopsy and could be included in this study, as we decided to include only definite SCJD patients, whereas all patients that remained with a clinical diagnosis of probable or possible sCJD were excluded from the analysis. For the non-CJD group, neuropathological confirmation of clinical diagnosis was not mandatory, allowing the inclusion of a larger number of non-CJD patients. This resulted in an over-representation of the non-CJD group in comparison with the sCJD group, which is also a statistical limitation of this study. This unbalance is also related to the increasing number of referrals that we and other reference laboratories for human prion diseases, have been experiencing over the years $[20,21]$, resulting in higher number of CSF samples tested that do not fulfil the WHO diagnostic criteria for possible sCJD, and, therefore, should not be tested in the first place.

From the commonly employed routine laboratory investigations for the diagnosis of sCJD (EEG, CSF analysis, and MRI), CSF 14-3-3 protein immunodetection was the most sensitive (98\%), followed by EEG $(55 \%)$ and MRI $(40 \%)$. This is in agreement with data from international collaborative studies [10, 13], and with the majority of the literature reporting the sensitivity of the 14-3-3 test $[7,11,12]$. However, the specificity of the 14-33 assay, in our population, was clearly sub-optimal (70 \%), lower than the reported in some previous studies $[11-13,20]$, but similar to recent prospective data from the 
UK and Canada [19, 36]. These data are very similar to what we had previously reported in a much smaller population (30 sCJD vs. 40 non-CJD patients) [14]. The poor specificity of the 14-3-3 assay could be related to several factors: the wide range of pathologies included in our control population that can lead to rapid and massive neuronal destruction; the tendency for a non-discriminatory application of the 14-3-3 assay as screening test for RPD in our country; and to the lack of standardization in the definition of positive results. The concern of declining specificity due to higher number of CSF 14-3-3 tests performed in various neurological conditions has been recently explored in a large multicenter longitudinal study [20], and this did not seem to be the case, with protein 14-3-3 test specificity remaining high and stable in the diagnosis of CJD during 10 years across centers. However, test specificity varied with respect to differential diagnosis and in line with our own study, a tendency for the 14-3-3 test to become more often false positive in acute neurological events (CNS tumors and encephalopathies) than in neurodegenerative and non-neurological forms of dementia was observed. The issue of standardization is an inherent limitation of the qualitative nature of the WB method used in the 14-3-3 assay, and as no standard approach exists, some authors consider all bands [11], while others only consider strong bands as positive $[13,19,20]$. When we reanalyze our data, considering only clear 14-3-3 bands as positive, an increase in specificity to $99 \%$, and with a decrease in sensitivity to $71 \%$, is observed. To avoid person-to-person bias of visual inspection and the difficult interpretation of weak bands, digital analysis of the 14-3-3 immunoblots with inclusion of recombinant 14-3-3 protein as standard has been employed by others [36, 37]. Also to overcome the difficulties of the WB method, several quantitative methods, such as ELISA and protein capture assays, have been developed [38, 39], resulting in a similar specificity, but also a lower sensitivity. Until now, such assays have not been used in clinical routine setting for various reasons: sub-optimal results, optimal conditions for the test unknown, comparative value not determined. Recently, a commercial ELISA kit for the gamma isoform of 14-3-3 protein has been made available [40] and has been validated in a large population of SCJD and non-CJD patients against the conventional WB method [41]. In our recently published work, we demonstrated, in a smaller cohort of definite sCJD and non-CJD, that this quantitative 14-3-3 ELISA is extremely promising, since it alone correctly classified $93 \%$ of cases [42].

t-Tau assay, on the contrary, proved to be extremely specific and only slightly less sensitive than the 14-3-3 assay for the differentiation between SCJD and non-CJD patients, as previously reported $[11,12,19,25,36]$. In the BIOMARKAPD European Project, many efforts were made in the last years to standardize t-Tau and p-Tau ELISA assays and improve pre-analytical handling practices [43-45]. Those trials made possible their broad use in biochemical diagnosis with high utility during the last few years. However, recent data from a large multicenter study [20] did not find t-Tau specificity overall increased in relation to $14-3-3$, but only when considering certain differential diagnostic groups, as potentially treatable inflammatory diseases. In our study, t-Tau higher specificity (94\%) was observed for the comparison between sCJD patients and almost all the differential diagnostic groups included in the non-CJD patients, even in patients that are known to suffer from taupathies, such as AD and FTLD, associated with modest increases in CSF t-Tau levels $[46,47]$. It is unclear why CSF Tau protein should be of greater specificity than 14-3-3, as the factors influencing the release of neuronal proteins in SCJD and other conditions are not fully understood. Moreover, while the sensitivity of 14-3-3 seemed to be influenced by the duration of disease at the time of lumbar puncture, as previously reported [10, 12-14, 19], t-Tau did not. Conflicting results exist regarding this issue, with some studies failing to find any influence of age and/or disease duration on t-Tau sensitivity [12, 14, 22], but other doing so [13, 19]. Another small study showed that t-Tau could also be a useful marker for sCJD in serum samples [48]. In a recent report, it was observed that in CJD individuals, t-Tau levels and $\mathrm{t}$-Tau to $\mathrm{p}$-Tau ratios increased over time, and the combination of increased t-Tau levels and increased t-Tau to p-Tau ratios in CJD patients has a very high specificity against important differential diagnoses [49].

In fact, a slight increase in CSF p-Tau levels in the sCJD group was observed in relation to the total non-CJD group. When we compared the p-Tau levels in sCJD patients, specifically with differential diagnostic groups associated with neurofibrillary pathology, namely AD and FTLD, no differences could be found (not shown). The reason for this small increase in p-Tau in the CSF of sCJD patients is not completely understood, as Tau hyperphosphorylation and neurofibrillary tangles are usually absent in sCJD. By contrast, the rapid neurodegenerative process, including axonal degeneration, in sCJD leads to an excessive liberation of Tau proteins, which causes the low p-Tau/t-Tau ratio. In Llorens et al. [50], p-Tau/t-Tau ratio discriminating power was higher in the differential diagnosis of sCJD when compared with other dementias than Tau alone. In our study, the combination of t-Tau with p-Tau in the $\mathrm{p}$-Tau/t-Tau ratio did not improve diagnostic accuracy in relation to t-Tau alone, but resulted in a similar improvement in specificity and overall accuracy in relation to 14-33 ( $p<0.0001)$, when considering all cases. This result is in line with a very recent study, reporting that the combined use of the 14-3-3 protein assay, t-Tau levels, and p-Tau/t- 
Tau ratio improved the specificity of diagnosis compared with the use of the $14-3-3$ protein assay alone (47 \% for 14-3-3 alone; $86 \%$ for 14-3-3 combined with t-Tau; and $91 \%$ for 14-3-3 combined with the p-Tau/t-Tau ratio) [31]. However, in the same study, very few patients had autopsyproven diagnosis, in contrast with our study, in which all sCJD patients had neuropathological confirmation. Besides, in our study, we have taken a new approach regarding the analysis of results, where we specifically addressed the 14-3-3 weak-positives (inconclusive) results in terms of biomarker's sensitivity and genotype influence.

The results from our logistic regression models show that the addition of t-Tau to 14-3-3 is significantly useful in the differentiation between SCJD and non-CJD patients ( $p<0.0001)$, but further inclusion of $\mathrm{p}$-Tau does not bring any additional discriminatory accuracy to the 14-33 model. This added value is particularly seen in terms of the specificity of the model and of the LR+, but not of sensitivity, which is already optimal for the model that only includes 14-3-3. In fact, the two sCJD patients that had a negative 14-3-3 result also tested negative for $\mathrm{t}$-Tau and for the p-Tau/t-Tau ratio. Furthermore, when we isolated 14-3-3 positive from weak-positive cases, we could see that t-Tau added value in the specificity and in the LR+ was only seen in the weak-positive cases. Again, even just for weak-positive cases, addition of p-Tau/t-Tau ratio to 14-3-3 had no impact on sensitivity but specificity and overall accuracy improved although not significantly $(p=0.0595)$. Worth mentioning, the only three cases of non-CJD patients that had a clear positive 14-3-3 result also tested positive for t-Tau and $\mathrm{p}-\mathrm{Tau} / \mathrm{t}-\mathrm{Tau}$ ratio.

These results were then corroborated by decision tree models, where in the model that forced 14-3-3 as the first variable, t-Tau was only useful in reducing the uncertainty of 14-3-3 weak-positive cases. From 108 patients with a weak-positive 14-3-3 test (28\% of the study population), the addition of $\mathrm{t}$-Tau cleared the results of 70 patients (that were either positive or negative for t-Tau), leaving only 38 patients (10\% of the study cohort; 31 non-CJD and 7 sCJD patients) with an inconclusive final classification. Interestingly, when no variables were forced into the model, $\mathrm{t}$-Tau was selected as the first decision variable, that alone only left 38 patients (10\% of the population) with intermediate results. This small group was then separated according to their 14-3-3 result, with weak-positive results treated as negative, and leaving no patients with an inconclusive result. Regardless of this experimental result, 14-3-3 is thus far still the only CSF marker included in the international guidelines for CJD. Our main focus still relies on demonstrating that t-Tau can be of added value in clinical routine diagnosis (especially on weak-positive cases) rather than testing its replacement feasibility.
Noteworthy, when we compared the AUC of the ROC curve obtained with t-Tau alone $(0.983 ; 95 \%$ CI 0.972-0.994) with either the AUCs of the ROC curves derived from the logistic regression model that included 14-3-3 combined with t-Tau or 14-3-3 combined with $\mathrm{p}$-Tau/t-Tau ratio, no differences were seen $(p=0.202$ and $p=0.3306$, respectively). This further indicates that t-Tau alone is a very good CSF marker for sCJD, and is not inferior to a combination of markers, as had been suggested by Hamlin and colleagues [25]. This is also in line with a 6 -year prospective study for SCJD in Canada, where the authors did not observe any evidence for diagnostic value of 14-3-3 beyond that available from Tau [36]. Given the current environment of enormous pressure for economical restraint, one has to consider the cost/benefit relation when faced the decision of choosing between the CSF markers (14-3-3 or Tau proteins). Logistic regression analysis and comparison of combined models performed in this study show that the input of $\mathrm{p}$-Tau protein as a third marker is not relevant (even in weak-positives only) facing the effect of t-Tau combined with 14-3-3, which already maximize diagnostic accuracy. With this in mind, our second decision model (combining 14-3-3 with t-Tau) would be preferable, as it would only require double marker testing in a much lower number of individuals, despite the fact that it happens at the expenses of specificity and not the sensitivity, which remains stable.

Moreover, due to the nature of the methodology employed in the t-Tau assay, a much larger number of samples can be tested in the same period of time than with the 14-3-3 WB assay and potentially reducing the diagnosis timeframe for weak-positive cases.

Regarding the molecular characteristics of the sCJD group, the frequency of the various PRNP genotypes was in accordance to the frequency distributions generally reported in the literature $[51,52]$. APOE genotyping was performed in a sub-set of the population, showing no differences in the distribution of the different genotypes between the two diagnostic groups. PRNP codon 129 polymorphism is known to influence the sensitivity of CSF protein 14-3-3 testing for sCJD. Overall, 14-3-3 was the most influenced marker by the patients characteristics, showing lower sensitivity for SCJD patients with longer disease duration $(\geq 12 \mathrm{M}),(p<0.0001)$, and heterozygous for PRNP codon $129(p=0.05)$. On the contrary, the sensitivity of t-Tau towards SCJD remained unchanged by these patient characteristics. Despite the fact that the relatively small number of patients might limit the conclusions taken from this analysis, these are in general agreement with the results from large population studies $[50,53]$. This difference in the protein markers sensitivity between sCJD sub-types might be accounted by the modulation of clinical phenotype by molecular characteristics. A host genotype 
effect has been reported, with codon 129 heterozygosity increasing the duration of illness, [52]. In fact, in our study, MV patients presented a longer disease course, when compared with the other genotypes $(p<0.05$ vs. VV and MM).

In summary, this study has shown that a combination of tests clearly improved sensitivity and specificity of sCJD diagnosis to optimal levels. Therefore, we propose that, besides 14-3-3 protein detection, CSF t-Tau should also be used in clinical practice. This would be specially advised in cases, where 14-3-3 gives a weak-positive result, or in cases with an atypical presentation, like patients with long disease duration and MV heterozygous for the PRNP codon 129. True pre-mortem laboratory diagnosis of human prion diseases may eventually be achieved with new approaches based for example on PrPSc [2, 3]. In the meantime, optimized application of known surrogate markers of neurodegeneration will continue to be at the forefront of sCJD diagnosis. In this context, our study indicates that in subjects, where a 14-3-3 result is already available, further assessment of Tau proteins will only be of added value in case of a weak-positive result. Nevertheless, additional studies exploring larger populations also with definite SCJD diagnosis are required to reproduce our current findings.

Acknowledgments The authors thank the Portuguese Surveillance Group for Human Prion Diseases, for support and implementation of the study. We also wish to thank all the physicians who sent us the CSF and blood samples and clinical and neuropathological information on suspected CJD cases: Centro Hospitalar e Universitário de Coimbra (Coimbra)—José Tomás, Isabel Santana, Hospital de Braga (Braga) — Sofia Rocha, Hospital de São João (Porto)—Carolina Garrett, Hospital de Santo António (Porto)-Bastos Lima, Centro Hospitalar entre Douro e Vouga (Santa Maria da Feira)—José Leal Loureiro, Hospital Pedro Hispano (Matosinhos)—Maria Manuela Costa, Hospital Fernando Fonseca (Amadora)- Simão Cruz, Hospital Egas Moniz (Lisboa)-Luísa Alves, and Hospital de Santa Maria (Lisboa)-José Pimentel. All authors have contributed to the work and agree with the presented findings. This study has not been published before and is not under review with any another journal. The work was supported in part by the Portuguese Foundation for Science and Technology (FCT) through JPND/0001/2011, under the aegis of an EU Joint Program-Neurodegenerative Disease Research (JPND) project and funded by FEDER through Competitive Factors Operational Program-COMPETE 2020 — as well as by the National Funds through FCT on the scope of strataegic CNC.IBILI UID/NEU/04539/ 2013 project.

\section{Compliance with ethical standards}

Ethical standards The study was performed in accordance with the ethical standards laid down in the 1964 Declaration of Helsinki. This study was approved by the Ethics Board of Coimbra University Hospital and all subjects or responsible caregivers, whichever appropriate, gave their informed consent.

Conflicts of interest The authors declare that they have no conflict of interest.

\section{References}

1. Pocchiari M, Poupolo M, Croes EA, Budka H, Gelpi E, Collins S, Lewis V, Sutcliffe T, Guilivi A, Delasnerie-Laupretre N, Brandel JP, Alperovitch A, Zerr I, Poser S, Kretzschmar HA, Ladogana A, Rietvald I, Mitrova E, Martinez-Martin P, de Pedro-Cuesta J, Glatzel M, Aguzzi A, Cooper S, Mackenzie J, van Duijn CM, Will RG (2004) Predictors of survival in sporadic CreutzfeldtJakob disease and other human transmissible spongiform encephalopathies. Brain 127:2348-2359

2. Atarashi R, Satoh K, Sano K, Fuse T, Yamaguchi N, Ishibashi D, Matsubara T, Nakagaki T, Yamanaka H, Shirabe S, Yamada M, Mizusawa H, Kitamoto T, Klug G, McGlade A, Collins SJ, Nishida N (2011) Ultrasensitive human prion detection in cerebrospinal fluid by real-time quaking-induced conversion. Nat Med 17:175-178

3. McGuire LI, Peden AH, Orrú CD, Wilham JM, Appleford NE, Mallinson G, Andrews M, Head MW, Caughey B, Will RG, Knight RS, Green AJ (2012) Real time quaking-induced conversion analysis of cerebrospinal fluid in sporadic CreutzfeldtJakob disease. Ann Neurol 72:278-285

4. Budka H, Aguzzi A, Brown P, Brucher JM, Bugiani O, Gullotta F, Haltia M, Hauw JJ, Ironside JW, Kl Jellinger (1995) Neuropathological diagnostic criteria for Creutzfeldt-Jakob disease (CJD) and other human spongiform encephalopathies (prion diseases). Brain Pathol 5:459-466

5. Poser S, Mollenhauer B, Kraubeta A, Zerr I, Steinhoff BJ, Schroeter A, Finkenstaedt M, Schulz-Schaeffer WJ, Kretzschmar HA, Felgenhauer K (1999) How to improve the clinical diagnosis of Creutzfeldt-Jakob disease. Brain 12:2345-2351

6. World Health Organization (1998) Report of a WHO consultation on global surveillance, diagnosis and therapy of human transmissible spongiform encephalopathies. WHO, Geneva, pp 8-11

7. Heinemann U, Krasnianski A, Meissner B, Varges D, Kallenberg K, Schulz-Schaeffer WJ, Steinhoff BJ, Grasbon-Frodl EM, Kretzschmar HA, Zerr I (2007) Creutzfeldt-Jakob disease in Germany: a prospective 12-year surveillance. Brain 130:1350-1359

8. Zerr I, Bodemer M, Gefeller O, Otto M, Poser S, Wiltfang J, Windl O, Kretzschmar HA, Weber T (1998) Detection of 14-3-3 protein in the cerebrospinal fluid supports the diagnosis of Creutzfeldt-Jakob disease. Ann Neurol 43:32-40

9. Lemstra AW, van Meegen MT, Vreyling JP, Meijering PH, Jansen GH, Bulk S, Baas F, van Gool WA (2000) 14-3-3 testing in diagnosing Creutzfeldt-Jakob disease: a prospective study in 112 patients. Neurology 55:514-516

10. Collins SJ, Sanchez-Juan P, Masters CL, Klug GM, van Duijn C, Poleggi A, Pocchiari M, Almonti S, Cuadrado-Corrales N, de Pedro-Cuesta J, Budka H, Gelpi E, Glatzel M, Tolnay M, Hewer E, Zerr I, Heinemann U, Kretszchmar HA, Jansen GH, Olsen E, Mitrova E, Alpérovitch A, Brandel JP, Mackenzie J, Murray K, Will RG (2006) Determinants of diagnostic investigation sensitivities across the clinical spectrum of sporadic Creutzfeldt-Jakob disease. Brain 129:2278-2287

11. Otto M, Wiltfang J, Cepek L, Neumann M, Mollenhauer B, Steinacker P, Ciesielczyk B, Schulz-Schaeffer W, Kretzschmar HA, Poser S (2002) Tau protein and 14-3-3 protein in the differential diagnosis of Creutzfeldt-Jakob disease. Neurology 58:192-197

12. Van Everbroeck B, Quoilin S, Boons J, Martin JJ, Cras P (2003) A prospective study of CSF markers in 250 patients with possible Creutzfeldt-Jakob disease. JNNP 74:1210-1214

13. Sanchez-Juan P, Green A, Ladogana A, Cuadrado-Corrales N, Sáanchez-Valle R, Mitrováa E, Stoeck K, Sklaviadis T, Kulczycki J, Hess K, Bodemer M, Slivarichová D, Saiz A, Calero M, 
Ingrosso L, Knight R, Janssens AC, van Duijn CM, Zerr I (2006) CSF tests in the differential diagnosis of Creutzfeldt-Jakob disease. Neurology 67:637-643

14. Baldeiras IE, Ribeiro MH, Pacheco P, Machado A, Santana I, Cunha L, Oliveira CR (2009) Diagnostic value of CSF protein profile in a Portuguese population of SCJD patients. J Neurol 256:1540-1550

15. Chapman T, McKeel DW Jr, Morris JC (2000) Misleading results with the 14-3-3 assay for the diagnosis of Creutzfeldt-Jakob disease. Neurology 55:1396-1397

16. Burkhard PR, Sanchez JC, Landis T, Hochstrasser DF (2001) CSF detection of the 14-3-3 protein in unselected patients with dementia. Neurology 56:1528-1533

17. Geschwind MD, Martindale J, Miller D, DeArmond SJ, UyeharaLock J, Gaskin D, Kramer JH, Barbaro NM, Miller BL (2003) Challenging the clinical utility of the 14-3-3 protein for the diagnosis of sporadic Creutzfeldt-Jakob disease. Arch Neurol 60:813-816

18. Machado A, Ribeiro M, Rodrigues M, Ferreira C, Baldeiras I, Ribeiro MH, Santana I, Almeida R, Castro L, Carpenter S (2009) Sporadic Creutzfeldt-Jakob disease causing a 2-years slowly progressive isolated dementia. Behav Neurol 21:175-179

19. Chohan G, Pennington C, Mackenzie JM, Andrews M, Everington D, Will RG, Knight RSG, Green AJE (2010) The role of cerebrospinal fluid 14-3-3 and other proteins in the diagnosis of sporadic Creutzfeldt-Jakob disease in the UK: a 10-year review. J Neurol Neurosurg Psychiatry 81:1243-1248

20. Stoeck K, Sanchez-Juan P, Gawinecka J, Green A, Ladogana A, Pocchiari M, Sanchez-Valle R, Mitrova E, Sklaviadis T, Kulczycki J, Slivarichova D, Saiz A, Calero M, Knight R, Aguzzi A, Laplanche JL, Peoc'h K, Schelzke G, Karch A, van Duijn CM, Zerr I (2012) Cerebrospinal fluid biomarker supported diagnosis of Creutzfeldt-Jakob disease and rapid dementias: a longitudinal multicentre study over 10 years. Brain 135:3051-3061

21. Klug GMJA, Wand H, Simpson M, Boyd A, Law M, Masters CL, Matěj R, Howley R, Farrell M, Breithaupt M, Zerr I, van Duijn C, Ibrahim-Verbaas C, Mackenzie J, Will RG, Brandel JP, Alperovitch A, Budka H, Kovacs GG, Jansen GH, Coulthard M, Collins SJ (2013) Intensity of human prion disease surveillance predicts observed disease incidence. J Neurol Neurosurg Psychiatry $0: 1-6$

22. Kapaki E, Kilidireas K, Paraskevas GP, Michalopoulou M, Patsouris E (2001) Highly increased CSF tau protein and decreased $\beta$-amyloid (1-42) in sporadic CJD: a discrimination from Alzheimer's disease? JNNP 71:401-403

23. Van Everbroeck B, Green AJE, Vanmechelen E, Vanderstichele H, Pals P, Sanchez-Valle R, Cuadrado Corrales N, Martin JJ, Cras $\mathrm{P}$ (2002) Phosphorylated tau in cerebrospinal fluid as a marker for Creutzfeldt-Jakob disease. JNNP 73:79-82

24. Bahl JM, Heegaard N, Falkenhorst G, Laursen H, Høgenhaven H, Mølbak K, Jespersgaard C, Hougs L, Waldemar G, Johannsen P, Christiansen M (2009) The diagnostic efficiency of biomarkers in sporadic Creutzfeldt Jakob disease compared to Alzheimer's disease. Neurobiol Aging 30:1834-1841

25. Hamlin C, Puoti G, Berri S, Sting E, Harris C, Cohen M, Spear C, Bizzi A, Debanne SM, Rowland DY (2012) A comparison of tau and 14-3-3 protein in the diagnosis of Creutzfeldt-Jakob disease. Neurology 79:547-552

26. Satoh K, Shirabe S, Tsujino A, Eguchi H, Motomura M, Honda H, Tomita I, Satoh A, Tsujihata M, Matsuo H, Nakagawa M, Eguchi K (2007) Total tau protein in cerebrospinal fluid and diffusion-weighted MRI as an early diagnostic marker for Creutzfeldt-Jakob disease. Dement Geriatr Cognit Disord 24:207-212

27. Pennington C, Chohan G, Mackenzie J, Andrews M, Will R, Knight R, Green A (2009) The role of cerebrospinal fluid proteins as early diagnostic markers for sporadic Creutzfeldt-Jakob disease. Neurosci Lett 455:56-59

28. Dorey A, Tholance Y, Vighetto A, Perret-Liaudet A, Lachman I, Krolak-Salmon P, Wagner U, Struyfs H, De Deyn PP, El-Moualij B, Zorzi W, Meyronet D, Streichenberger N, Engelborghs S, Kovacs GG, Quadrio I (2015) Association of cerebrospinal fluid prion protein levels and the distinction between Alzheimer disease and Creutzfeldt-Jakob disease. JAMA Neurol 72:267-275

29. Riemenschneider M, Wagenpfeil S, Vanderstichele H, Otto M, Wiltfang J, Kretzschmar H, Vanmechelen E, Förstl H, Kurz A (2003) Phospho-tau/total tau ratio in cerebrospinal fluid discirminates Creutzfeldt-Jakob disease from other dementias. Mol Psychiatry 8:343-347

30. Buerger K, Otto M, Teiperl SJ, Zinkowski R, Blennow K, DeBernardis J, Kerkman D, Schröeder J, Schönknecht P, Cepek L, McCulloch C, Möller HJ, Wiltfang J, Kretzschmar H, Hampel H (2006) Dissociation between CSF total tau and tau protein phosphorylated at threonine 231 in Creutzfeldt-Jakob disease. Neurobiol Aging 27:10-15

31. Hyeon JW, Kim SY, Lee J, Park JS, Hwang KJ, Lee SM, An SA, Lee MK, Ju YR (2015) Alternative application of Tau protein in Creutzfeldt-Jakob disease diagnosis: improvement for weakly positive 14-3-3 protein in the laboratory. Sci Rep 5:15283

32. Machado A, Soares H, Antunes H, Magalhães Z, Ferreira C, Baldeiras I, Ribeiro MH, Santana I, Ramalheira J, Castro L, Carpenter S (2008) Variant Creutzfeldt-Jakob disease: the second case in Portugal and in the same geographical region. JNNP 79:180-182

33. Mattsson N, Andreasson U, Persson S, Arai H, Batish SD, Bernardini S, Bocchio-Chiavetto L, Blankenstein MA, Carrillo MC, Chalbot S, Coart E, Chiasserini D, Cutler N, Dahlfors G, Duller S, Fagan AM, Forlenza O, Frisoni GB, Galasko D, Galimberti D, Hampel H, Handberg A, Heneka MT, Herskovits AZ, Herukka SK, Holtzman DM, Humpel C, Hyman BT, Iqbal K, Jucker M, Kaeser SA, Kaiser E, Kapaki E, Kidd D, Klivenyi P, Knudsen CS, Kummer MP, Lui J, Lladó A, Lewczuk P, Li QX, Martins R, Masters C, McAuliffe J, Mercken M, Moghekar A, Molinuevo JL, Montine TJ, Nowatzke W, O'Brien R, Otto M, Paraskevas GP, Parnetti L, Petersen RC, Prvulovic D, de Reus HP, Rissman RA, Scarpini E, Stefani A, Soininen H, Schröder J, Shaw LM, Skinningsrud A, Skrogstad B, Spreer A, Talib L, Teunissen C, Trojanowski JQ, Tumani H, Umek RM, Van Broeck B, Vanderstichele H, Vecsei L, Verbeek MM, Windisch M, Zhang J, Zetterberg H, Blennow K (2011) The Alzheimer's Association external quality control program for cerebrospinal fluid biomarkers. Alzheimers Dement 7:386-395

34. Crook R, Hardy J, Duff K (1994) Single-day apolipoprotein E genotyping. J Neurosci Methods 53:125-127

35. Geschwind MD, Shu H, Haman A, Sejvar JJ, Mille BL (2008) Rapidly progressive dementia. Ann Neurol 64:97-108

36. Coulthart MB, Jansen GH, Olsen E, Godal DL, Connolly T, Choi BC, Wang Z, Cashman NR (2011) Diagnostic accuracy of cerebrospinal fluid protein markers for sporadic Creutzfeldt-Jakob disease in Canada: a 6-year prospective study. BMC Neurol $11: 133$

37. Satoh K, Tobiume M, Matsui Y, Mutsukura K, Nishida N, Shiga Y, Eguhchi K, Shirabe S, Sata T (2010) Establishment of a standard 14-3-3 protein assay of cerebrospinal fluid as a diagnostic tool for Creutzfeldt-Jakob disease. Lab Investig 90:1637-1644

38. Kenney K, Brechtel C, Takahashi H, Kurohara K, Anderson P, Gibbs CJ Jr (2000) An enzyme-linked immunsorbent assay to quantify 14-3-3 proteins in the cerebrospinal fluid of suspected Creutzfeldt-Jakob disease. Ann Neurol 48:395-398

39. Green AJ, Ramljak S, Muller WE, Knoght RS, Schroeder HC (2002) 14-3-3 in the cerebrospinal fluid of patients with variant 
and sporadic Creutzfeldt-Jakob disease measured using a capture assay able to detect low levels of 14-3-3 protein. Neurosci Lett 324:57-60

40. Matsui Y, Satoh K, Miyazaki T, Shirabe S, Atarashi R, Mutsukura K, Satoh A, Kataoka Y, Nishid N (2011) High sensitivity of an ELISA kit for detection of the gamma-isoform of 14-3-3 proteins: usefulness in laboratory diagnosis of human prion disease. BMC Neurol 11:120-129

41. Schmitz M, Ebert E, Stoeck K, Karch A, Collins S, Calero M, Sklaviadis T, Laplanche JL, Golanska E, Baldeiras I, Satoh K, Sanchez-Valle R, Ladogana A, Skinningsrud A, Hammarin AL, Mitrova E, Llorens F, Sun Kim Y, Green A, Zerr I (2015) Validation of 14-3-3 protein as a marker in sporadic CreutzfeldtJakob disease diagnostic. Mol Neurobiol 53(4):2189-2199

42. Leitão MJ, Baldeiras I, Almeida MR, Ribeiro MH, Santos AC, Ribeiro M, Tomás J, Rocha S, Santana I, Oliveira CR (2016) Sporadic Creutzfeldt-Jakob disease diagnostic accuracy is improved by a new CSF ELISA 14-3-3 $\gamma$ assay. Neuroscience 13(322):398-407

43. Del Campo M, Jongbloed W, Twaalfhoven HAM, Veerhuis R, Blankenstein MA, Teunissen CE (2015) Facilitating the validation of novel protein biomarkers for dementia: an optimal workflow for the development of sandwich immunoassays. Front Neurol 6:1-10

44. Andreasson U et al (2015) A practical guide to immunoassay method validation. Front Neurol 6:1-8

45. Leitão MJ, Baldeiras I, Herukka SK, Pikkarainen M, Simonsen A, Perret-Liaudet A, Fourier A, Quadrio I, Mota Veiga P, Oliveira CR (2015) Chasing the effects of pre-analytical confounders-a multicentre study on CSF biomarkers. Front Neurol 6:153

46. Green AJE, Harvey RJ, Thompson EJ, Rossor MN (1999) Increased tau in the cerebrospinal fluid of patients with frontotemporal dementia and Alzheimer's disease. Neurosci Lett 259:133-135

47. Baldeiras I, Santana I, Leitão MJ, Ribeiro MH, Pascoal R, Duro D, Lemos R, Santiago B, Almeida MR, Oliveira CR (2015) Cerebrospinal fluid $A \beta 40$ is similarly reduced in patients with frontotemporal lobar degeneration and Alzheimer's disease. J Neurol Sci 358(1-2):308-316

48. Noguchi-Shinohara M, Hamaguchi T, Nozaki I, Sakai K, Yamada M (2011) Serum tau protein as a marker for the diagnosis of Creutzfeldt-Jakob disease. J Neurol 258:1464-1468

49. Skillbäck T, Rosén C, Asztely F, Mattsson N, Blennow K, Zetterberg H (2014) Diagnostic performance of cerebrospinal fluid total tau and phosphorylated tau in Creutzfeldt-Jakob disease: results from the Swedish mortality registry. JAMA Neurol 71:114

50. Llorens F, Schmitz M, Karch A, Cramm M, Lange P, Gherib K, Varges D, Schmidt C, Zerr I, Stoeck K (2015) Comparative analysis of cerebrospinal fluid biomarkers in the differential diagnosis of neurodegenerative dementia. Alzheimers Dement 12(5):577-589. doi:10.1016/j.jalz.2015.10.009

51. Calero O, Bullido MJ, Clarimón J, Frank-García A, MartínezMartín P, Lleó A, Rey MJ, Rábano A, Blesa R, Gómez-Isla T, Valdivieso F, de Pedro-Cuesta J, Ferrer I, Calero M (2011) Genetic cross-interaction between APOE and PRNP in sporadic Alzheimer's and Creutzfeldt-Jakob diseases. PLoS One 6:e22090

52. Gmitterová K, Heinemann U, Bodemer M, Krasnianski A, Meissner B, Kretzschmar HA, Zerr I (2009) 14-3-3 CSF levels in sporadic Creutzfeldt-Jakob disease differ across molecular subtypes. Neurobiol Aging 30:1842-1850

53. Karch A, Hermann P, Ponto C, Schmitz M, Arora A, Zafar S, Llorens F, Müller-Heine A, Zerr I (2014) Cerebrospinal fluid tau levels are a marker for molecular subtype in sporadic Creutzfeldt-Jakob disease. Neurobiol Aging 36:1964-1968 